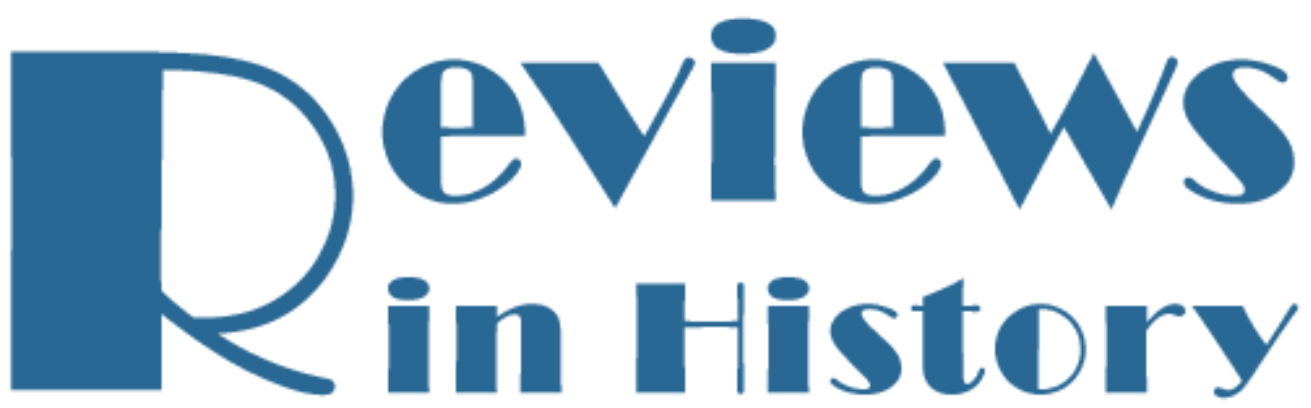

Published on Reviews in History (http://www.history.ac.uk/reviews)

\title{
Empire and Information: Intelligence Gathering and Social Communication in India, 1780-1870
}

\section{Review Number:}

2032

Publish date:

Thursday, 8 December, 2016

Author:

Christopher Bayly

ISBN:

9780521570855

Date of Publication:

1996

Price:

$£ 85.00$

Pages:

428pp.

\section{Publisher:}

Cambridge University Press

\section{Publisher url:}

http://www.cambridge.org/gb/academic/subjects/history/south-asian-history/empire-and-informationintelligence-gathering-and-social-communication-india-17801870?format=PB\&isbn=9780521663601

\section{Place of Publication:}

\section{Cambridge}

\section{Reviewer:}

Ricardo Roque

Knowledge is power. Over the last three decades this old aphorism of political philosophy has been central to the study of colonialism in history, anthropology, and literary and cultural post-colonial studies. Revised and re-launched in social theory by Michel Foucault, the theme gained momentum after the publication of Edward Said?s highly influential book, Orientalism, in 1978. Said proposed a critical examination of Western Orientalist scholarship as both a cultural system of (mis-)representation of otherness, and an inherently political project of colonial domination. In these terms, Western knowledge of ?the Orient? reflected little more than European cultural conventions, fantasies, and fictions. Said?s argument set out the terms around which the debate on colonial knowledge was to evolve. The early developments of this debate relied in large part on the study of British and South Asian material, and due to the vitality of the Subaltern Studies collective, (British) India remained at the forefront of discussions. Inspired by Said, Indologist Ronald Inden wrote Imagining India, while literary critic Homi Bhabha revised Said?s arguments using the notion of hybridity. In parallel, anthropologist historian Bernard S. Cohn (followed by his student Nicholas Dirks) explored how the British colonial state relied on cultural technologies and classificatory techniques to 
conquer, dominate, and rule indigenous people in India.

In the early 1990s, this invigorating wave of scholarship set new challenges to empiricist imperial historiography, stubbornly suspicious of ?theory? and reliant on the inherent value of European ?sources?. The idea of the hegemonic, epistemologically biased, and Eurocentric nature of colonial discourse was shared by much post-colonial academic writing on colonialism and, particularly, on India. However, this avowedly anti-colonialist and strictly textualist agenda nevertheless had severe limitations. Critical voices of this over-emphasis soon appeared. Authors as distinct in their approaches as historians David Washbrook, or anthropologist Nicholas Thomas, for instance, wrote important critiques of this discourse-centred turn in colonial studies. Many questions, however, still remained to be answered within imperial historiography. Was colonial knowledge merely a matter of European power and domination? Could the constellation of ?colonialism and knowledge? be approached differently? Might alternative pathways and nuances of knowledge and power be revealed within the archival record? Was it possible, for example, to recover the imprint left by indigenous people and cultures on the social, intellectual, and political fabrication of colonial knowledge ? could, in other words, a historical account of colonial knowledge/power include Indian, rather than simply British, agents, social relations, and even categories and knowledge forms?

Written at the peak of this effervescent international debate, the late C. A. Bayly?s Empire and Information (1) broke new ground and presented fresh and provocative perspectives. The book offers a meticulously researched social and intellectual history of intelligence-gathering and social communication in north India, over the course of a century of British rule, between 1780 and 1870. By the time it was published in 1996 (the paperback edition was published in 1999), the author, Vere Harmsworth Professor of Imperial and Naval History at Cambridge University, was already a reputed historian of British Imperial and Indian history. Bayly entered the ?colonial knowledge? debate from a historical sociological angle that contrasted with post-colonial literary methods. Uneasy with Said?s depiction of Orientalism, but also detached from conservative empiricism, he engaged with theory to propose alternative historical interpretations. This is, then, an ambitious work that engaged directly with the broader debate on orientalism and colonial knowledge, and accordingly constitutes a significant contribution to the field beyond the chronological scope of the 1800s, the history of India, or the British Empire. The archive-grounded method, fluid chronological narrative, and sober language does not obscure the broader conceptual potency of the book. In my view, then, Empire and Information reads principally as a historical and sociological critique of the related categories of ?colonial knowledge?, ?Orientalism?, and ?power? as they were then in common academic usage ? or, to appropriate Bayly?s own words, it is an exercise in ?deconstructing the notion of orientalism? (p. 370).

In effect, it was this conceptual energy that most impressed me when I first read the book as a young graduate student. I was moving from Lisbon to my first academic job in the Azores, having just completed a MA thesis on warfare, physical anthropology and colonialism in late 19th-century Goa (Portuguese India). I read the book, in its paperback edition, while I struggled to transform the thesis into a publication. From my Lusophone standpoint, I felt uneasy, like C. A. Bayly, with the category ?orientalism? and with excessive criticism of the complicities between knowledge and power. Bayly?s call to examine vulnerability and indigenous agency in colonial knowledge felt like a breath of fresh air. It prompted me to rethink my approach to colonial history, by venturing profoundly into anthropological theory and methodologies. It took me to Cambridge, yet paradoxically away from India. It led me to a doctoral dissertation that ? both with and beyond Bayly?s arguments on engagement ? explored colonial violence and indigenous headhunting cultures in ?Portuguese Timor?, as a complex symbiosis that I conceptualized as mutual parasitism. Thus, in a sense, the resulting monograph, Headhunting and Colonialism (2), carries the imprint of Empire and Information: the ambition for conceptual vigour, the determination to draw on histories of colonial weakness and crosscultural engagement to produce general insights into the nature of the colonial phenomenon. Certainly, the book?s conceptual argument is bounded by the particular historical-geographical context within which it is set: British/Indian interactions in 18th- and 19th-century (North) India. In this review, however, I will not concentrate on issues of historical content and on its strengths and limitations in comparative imperial history. Its empirical specificities notwithstanding, I will approach this book as a work of conceptual breadth 
about the intricate world of colonialism and knowledge.

$*$

The British Empire in India was firstly, Bayly?s argument begins, an ?empire of information?, even, or especially, during its most dramatic moments, such as the famous Indian Uprising of 1857, often referred to as the ?Mutiny?. The overarching thesis is that British conquest of India (and north India in particular) depended principally upon the colonizers? capacity to manipulate Indian knowledge about the Indian world. This was a process of selective and, sometimes, distorted incorporation of agents and features of the precolonial indigenous information order. Colonialism in India should accordingly be viewed as a European venture of conquest and violence, established above all on ?knowledge? and ?information? (Bayly differentiates analytically between these two related terms: ?information? referring to a looser day-to-day realm of widely shared claims to truth; and ?knowledge? to a ?socially organized and taxonomised information? (p. 4)). Bayly?s point on the significance of knowledge for the colonial conquest of India resonates with Said and his followers? emphasis on the determining role of knowledge in colonial domination. Yet Bayly?s argument follows a different direction as regards the role of indigenous society. Rather than existing passively as an object of European misrepresentation, the indigenous world did play an integral, necessary, and active part in the making of colonial processes of knowledge and information.

The book?s main premise is that indigenous societies and cultures cannot be excluded from the explanation of how and why the colonial knowledge/power nexus actually succeeded or ultimately failed. It explores how two distinct ?systems? ? British political, military, and state intelligence in North India, on the one hand; and ?communication and the movement of knowledge? within Indian society, on the other? ?overlapped and interpenetrated? (however incompletely and equivocally) to support or undermine British domination; and how, finally, this same partial overlap laid the grounds for Indian political critiques and even the emergence of Indian nationalism. (p. 7) ?European rule over Asians and Africans?, suggests Bayly, ?could not have been sustained without a degree of understanding of the conquered societies. In India, colonial knowledge was derived from a considerable extent from indigenous knowledge, albeit torn out of context and distorted by fear and prejudice? (p. 7). Empire and Information, then, is not about an abstract Western project of writing, thought, or imagination. Eugene F. Irshchik?s Dialogue in History, a work arguing for a dialogical approach to knowledge in colonial South Asia, had just been published in 1994.(3) Bayly sought inspiration in Irshchik?s insight to propose a tale of two knowledge-worlds in complex ?engagement?: how it came into being and how it changed over time. To this purpose, Empire and Information expands and redefines the notion of colonial knowledge more widely. It proposes to reinvent it as a fractured, heterogeneous, and plural formation that results from the dialogues, reciprocal manipulations, overlaps, equivocations, and gaps between European and Indigenous social, cultural, and political agents and realities in loco. ?Our understanding of ?colonial discourse??, declared Bayly, ?must reflect the pervasiveness of Indian agency, of the Indian intellectual challenge, and of Indian cultural vitality? (p. 314). The production, circulation, and contents of colonial knowledge must consider indigenous agents, cultural recourses, and social life. European constructs are not indigenous terra nullius. In short, the book proposes not only to expose the contradictory, contingent, and varied facets of colonial knowledge(s), but also to move beyond the equivalence between the terms ?European? and ?colonial?, in order to bring indigeneity (or, in Bayly?s terms, ?indigenous agency?) back into the understanding of colonial knowledge.

Bayly adds yet another important dimension to this reconceptualising of colonial knowledge. He sets out to reflect on how British imaginaries of India often derived from an emotional and affective sense of vulnerability and fear, rather than from a self-professed rationalization of supremacy: ?The meeting between British and Indian agencies was riven by suspicion, distortion and violence?. Bayly states in the introduction: ?For here, at the point of intersection between political intelligence and indigenous knowledge, colonial rule was at its most vulnerable? (p. 3). For Bayly, the European colonizer as a historical character does not conform to the conventional image of an omnipotent and self-confident actor. Rather, it is a human character fraught with uncertainty and fear of the ?native? incomprehensible communicative powers ? a fear from which the colonizers? worst misrepresentations and violence could derive. ?The basic fear of the colonial official or settler was, consequently?, he remarks, ?his lack of indigenous knowledge and ignorance 
of the ?wiles of the natives?. He feared their secret letters, their drumming and ?bush telegraphy? and the nightly passage of seditious agents masquerading as priests and holy men? (p. 6). This bold claim aimed at revising the knowledge/power association,as Said?s and (some of) Foucault?s writings depicted it: ?we shall suggest?, Bayly writes in a footnote, ?that in pre-colonial and colonial times the emergence of systems of knowledge could equally well reflect the weaknesses of power and legitimacy, or situations of social competition. Assertive ?knowledges? might grow up on the troubled margins of power.? (note 49, p. 25) Thus ?colonial knowledge? ? especially Western fantasies of ?native Otherness? ? can be understood as a manifestation of the ignorance, fear, panics and fragility of colonizers: ?British assessments of crime, religion and native lethargy?, Bayly argues, ?were more often reflections of the weakness and ignorance of the colonisers than a gauge of hegemony? (p. 143). Bayly?s provocative analytical turn suggests the very aphorism ?knowledge is power? should be reconsidered, in the light of a complementary, yet reversed, axiom: knowledge is weakness, knowledge is fear. Hence Bayly?s tour de force, to which I will continue to call attention. In placing Indian agents, information, and networks inside, rather than simply outside, the core of a British colonial order that was inherently violent and yet fragile, vulnerable, incomplete, erroneous, fractured and even irrational, Empire and Information fielded an innovative challenge to commonly accepted notions of colonial knowledge and Orientalism.

$*$

One reason for this achievement, I believe, lay in the book?s combination of analytical insight with archival rigour and a close attention to the contingencies of historical change. For, as the book demonstrates, orientalist conceptions are not fixed conditions but historical processes; their configurations and contents change over time and across space. The long engagement between British and Indian knowledge is explored in a partly thematic, partly chronologically, structured narrative that covers an impressive array of topics, including languages, actors, themes, regions, and areas of British and Indian life and thought. Bayly draws on then recent social theory ? e.g., sociologist Manuel Castells? notion of ?information order?, and political philosopher Jurgen Habermas?s idea of the Western ?bourgeois public sphere? ? to create what has since become a set of influential conceptual notions, such as ?information panics?, ?affective knowledge?, or ?Indian ecumene?.

The book?s first chapter takes us to Indian ?pre-colonial? (before 1780) systems of surveillance, literacy cultures, and information management? the indigenous foundations of what was to become, in part, the information order of British India under the East India Company. The chapter describes the decentralized Hindu and Mughal systems of state surveillance based on complex networks of spies and runners (harkaras) that carried messages and news to the rulers. It was this decentralized surveillance network of runners and spies that, as shown in chapter two, the British would be ?forced to master and manipulate? and basically incorporate during the years of conquest, up till about 1830. These same networks were volatile, and could easily escape control and be turned against the Mughal rulers and, later on, the British rulers as well.

The pre-colonial information order, however, was not restricted to the surveillance networks of spies, runners, and elite scribes (the munshis). It also encompassed a range of other knowledge formations that, as Bayly emphasizes throughout the book, the British were not able to either access or effectively master. For, if it is true that ?the colonial information order was erected on the foundations of its Indian precursors? (p. 179), it is also true that the structure did not coincide perfectly with the whole of its indigenous foundations; the overlap was neither clear nor absolute. The Indian information order was able to preserve a certain degree of autonomy, and this was one important reason for the relative weakness of British power. In contrast with their successors, Indian rulers had access to two types of knowledge: ?patrimonial knowledge? (?deep and detailed knowledge? of the ruler?s nobles and magnates) and ?affective knowledge? (?the knowledge gained from participation in communities of belief and marriage?) (p. 17). Information circulated across society in more unofficial circuits as well, often as rumor and gossip, in the day-to-day exchanges of the Indian bazars or through the women acting as marriage-brokers.

The following two chapters examine how the successes and failures of the British military conquest of India between 1785 and 1815 depended on the gathering of reliable intelligence about India and Indians. Before 
conquest began, British knowledge of India was but a patchy type of ?pragmatic information? predicated upon the basically commercial orientation of the Company. This would change dramatically during the conquest. In north India, as Bayly demonstrates, the British were able to worm their way into the volatile Mughal dynastic states and its elites, and turn these states? information networks and agents to their own political and military advantage. The resulting colonial information order was, therefore, largely built upon the inherited ?pre-colonial? Mughal system of intelligence-gathering and newswriting. British intelligence, then, resulted from Indian knowledge and Indian networks of daks, harkaras and munshis: ?As with the Mughals?, Bayly observes, ?post and palankin routes (daks) became the arteries of British India? (p. 58). The British could hardly grasp many of the aspects of this system in indigenous terms ? for instance, Bayly notes, they never understood the subtle politics of the Persian flowery writing-style (pp. 77?8). Yet, a pragmatic parasitical appropriation of indigenous information routes and their specialized writers and news agents became conditional for British military expansion. For Bayly, this intelligence system made from, and in the image of, pre-colonial India explains why the British conquest of the north Indian plains was successful. Similarly, intelligence (or, rather, lack of it) explains why the Europeans failed to conquer the hill regions. For the contours of the British engagement with the Indian pre-colonial world also depended on social, political, and geographical inscription: ?the further the British went from Delhi, the weaker became [their] purchase on indigenous society? (p. 140).

The challenges of the British wars in Nepal, Burma and Punjab are explored in chapter three, in order to make this point. In contrast with north Indian plains, the British encountered impermeable information systems in Nepal and in Burma, which they were unable to use to their benefit. The incapacity to conquer the country resulted from the incapacity to possess and manipulate indigenous information mechanics. Chapter six follows the historical changes of this unequal engagement in north India, culminating in the Uprising of 1857, (explored further in chapter nine). It investigates how, after 1830, the British engagement with the north Indian information order changed into an administrative apparatus of rule that ?subordinated and recasted Indian knowledge? and informants in favor of the supposedly ?superior? values of ?education? and ?useful knowledge?. However, even then, the British ?information revolution? did not reach everywhere. Indian knowledge, especially at a lower level of the Indian social structure, was not only intellectually active and reactive to British intrusion, as it continued to work independently of British interference. It was from within the overlaps and gaps of this information order that a major Indian rebellion sprang in 1857. This insurgency revealed both the vitality of Indian ?subjugated knowledges? and the fragility of the intelligence system the British had been able to forge. Significantly, only a technological advantage in the information battle allowed the British to survive the struggle: their ability to mobilize an international system of communication through the use of the electric telegraph.

In Nepal and Burma, British intelligence failures did not preclude the orientalist fantasies of otherness, concerning the wild Gurkhas or the myth of the ?white elephant?, for example. Following his analysis of conquest, Bayly sees in this correlation between intelligence-failure and orientalist imaginaries a more general pattern of colonial knowledge. The more deficient the indigenous-based intelligence, the more ignorant the British, the more fictitious, invented and biased were British constructs about Indian people. Knowledge gaps and ignorance on the social margins can thus explain orientalist prejudice and othering. British stereotypes of the Indian ?other? as primitive, barbarian, or inferior often derived from situations of political weakness and lack of (Indian-based) information. In its most extreme manifestations (such as Thuggee, or widow-burning), these misapprehensions of Indian reality result from a kind of emotionally and irrationally driven fear and panic about that same imagined Indian ?other?. The notion of ?information panics?, introduced in chapter four, is an attempt at giving an analytical response to these considerations. In a pair of valuable passages, Bayly argues that:

?Away from the hubs of British power and below the level of the district office the old intelligence communities held their place. It was in the zone of ignorance where the knowledgeable colonial institutions met, but failed to mesh with, the sentiment of the knowing people of the locality, that the stereotypes of Thugs, criminal guilds, religious fanatics and well- 
poisoners were hatched. In this space arose the information panics which periodically convulsed expatriate British society in India. [?] Thus when information panics and ideological frenzies overtook administration [?] it was evidence of the limitations of colonial power and knowledge, not the effectiveness of its projection on society. As with panics with witches, heretics, Jesuits and freemasons in Europe it reflected the weakness of the new quasi-bureaucratic state in its own hinterland rather than premeditated attempts to master society. The margins of policing were, therefore, the nursery of practical orientalising where the social Other was discovered? (p. 143 and p. 171).

Albeit loosely defined, the notion of ?information panics? offers perhaps Bayly?s most innovative deconstructive critique of the ?colonial knowledge? category. Through the notion of information panics, Bayly is realizing his reversal of the statement ?knowledge is power? by revealing knowledge ? and, principally, Orientalist othering ? to be fear. Information panics come about when and where control and power is weak or absent. This fear-based dynamic is based on contingent sociopolitical conditions.(4) Consequently, the epistemological failures and biases of orientalism(s) are not to be understood as a condition or a property of ?colonial knowledge? as such. They should be approached, in the context of a ? sociology of knowledge on the margins of government? (p. 179), as a result of the sociological circumstances that express the faulty and incomplete nature of power.

Bayly complements this position with a set of studies that investigate, on the one hand, the incomplete, distorted, but also plural, fragmented, and contradictory nature of ?colonial knowledge? (not a ?monolith? but a plurality of situated knowledges, ?imperfectly linked?, the author notes, (p. 169)); and, on the other hand, the epistemic and socio-political engagement between British and Indian knowledge systems and practitioners. The latter dimension is particularly worth highlighting, since it relates to the author?s central purpose to identify indigenous agency in colonial conceptions of the indigenous. To begin, colonial knowledge is not a mere misrepresentation of indigenous worlds. It is also the site where signs of these worlds and voices come to our attention, even if inaccurately registered. Colonial knowledge is in many cases based on the inclusion of indigenous cultural elements and ?voices?, albeit distorted and transformed: ?in so many respects, colonial knowledge represented a partially accurate reflection of Indian society and politics distorted by the fear and greed of both colonisers and colonised? (p. 149). The concept of ?caste? is the prime example, according to Bayly. Arguing against those scholars who considered (and may still consider) it as mere European ?invention? ex nihilo, he suggests caste did pre-exist as an Indian concept, later being used and transformed by the British in their taxonomies (p. 169). Thirdly, many Orientalist texts and readings were not effectively read or used in practice, ?learned Orientalism ever acted widely or deeply on society? (p. 169). Fourthly, developments in colonial knowledge should be understood as an outcome of reciprocally active engagements, although permeated by inequalities. Indigenous agency must be taken into consideration as a generative constituent of colonial knowledge, including colonial sciences and medicine. 
The exploration of what Bayly designates as the ?Indian ecumene? in chapter five (an Indian variant of the Habermasian public sphere) is thus an effort to expose the vitality of Indian agency, as concerns political theory and a culture of social debate. By the same token, chapters seven and eight constitute a composition of case-studies, ?engagements between different types of British and Indian knowledge and their practitioners? (p. 311). Here Bayly moves beyond state intelligence and warfare to describe a set of early 19th-century controversies involving British and Indian agents concerning astronomy, medicine, language, and geography. The purpose is to reveal how orientalism, explored here in its more learned and scientific variants, is best conceived of an ?arena of debate? and ?unequal dialogue? where Indian elites were intellectually active. The British could in turn exclude or dismiss the authority of Indian practitioners while, at the same time, seeking to appropriate indigenous knowledge, taking from the Indian repertoire much more than they gave (pp. 360, 169, 311). British ??knowledge??, Bayly concludes, ?though it usually asserted superiority, was unstable, ambiguous, and often derivative from Indian sources.? (p. 311) Colonial knowledge is not power alone ? it is also weakness uncovered. Orientalism is not European imagination simply? it is colonial knowledge derived from Indian sources. Thus Bayly indefatigably reminds his readers to approach orientalism deconstructed.

Empire and Information is a remarkably rich book and a classic piece of scholarship on imperial history. Its broad interdisciplinary appeal makes it readable in many different ways. As the author acknowledges (although perhaps too briefly), the specificities of British presence in India set limits to extrapolating a similar high-level of European dependence on indigenous information beyond the Indian colonial case. In concrete, Bayly conjectures a contrast between his Anglo-Indian story with the case of British southern Africa, where, in his opinion, a racist ?apartheid? ideology and a stronger white or creole community led to distinct indigenous and colonial information orders, and to clear-cut European imageries of ?native otherness? (see pp. 7, 142). Coming scholars, most notably historian Martin Thomas, have reassessed the historical scope of Bayly?s hypothesis in comparative imperial history. The focus on a dichotomous relationship (British/Indians) may leave out exchanges between Europeans (other than the British) and the Indian order, especially before the 1700s. Two centuries of Portuguese articulations with Indian knowledge orders, for instance, preceded British rule in India and go almost without mention in the book. Aside from such considerations concerning historical content, however, I have attempted to call attention to what is, in my opinion, the book?s powerful conceptual storyline, which continues to raise important questions and carry broader implications for imperial history and post-colonial studies today. I refer to Bayly?s historicalsociological challenge to deconstruct ?colonial knowledge?. Written from the perspective of a social and intellectual imperial historian, this deconstruction followed, in my opinion, two principal axes: first, the indigenous constitution of colonial knowledge, through a focus on processes of co-production; second, the fear-driven origins of knowledge and power, through the addition of a knowledge/fear-panic-weakness nexus to the conceptualizing of colonialism.

No wonder the book was widely praised by most of its early reviewers, and its future impact beyond the historiography of India and the British Empire rightly anticipated. Bayly?s insights into state intelligencegathering, Orientalism, information panics, and the significance of indigenous mediators have proved vital to subsequent developments in British imperial history, in other historiographies of European empires, and in historiographies of science and empire more widely. No wonder, too, that it provoked critiques and some passionate reactions: at the heart of the book is a comprehensive intellectual challenge to the categories ?colonial knowledge? and ?orientalism? that interfered polemically with post-colonial studies in the wake of Said?s Orientalism. The debate may not be closed, but Empire and Information suggested new avenues of inquiry. For some critics, the claim to recover the engagement from an ?Indian perspective? was a promising, yet unfulfilled project. The book?s analytical solution to the problem of intercultural engagement ? the idea of ?unequal dialogue? ? also looks vaguely conceptualized, especially as regards the issues of violence and difference. Equally unsatisfactory is the concluding proposal to replace ?othering? with a kind of muddle, ?syncretism?, as ?the most common epistemological strategy of colonial rule? (p. 371). All these 
questions, however, continue to reveal the inspirational strength of the book. Since its publication, Empire and Information has been changing the way students of colonialism and empires approach the issues of knowledge and information in theory, history, and the social sciences. 20 years ago, it changed my personal and intellectual life. It took me beyond the comfort of received assumptions about colonialism and power, and it made me travel to places and explore ideas that I would not otherwise had considered. I trust this outstanding and thought-provoking work will continue to incite new debates and inspire young scholars to pursue their own original intellectual adventures.

\section{Notes}

1. I thank Diogo Ramada Curto by introducing me to the work of C. A. Bayly, in the late 1990s. I am grateful to my dear historian friends, Kim A. Wagner and Ângela Barreto Xavier, for reading an earlier draft and offering valuable comments. My greatest debt of gratitude is to my former $\mathrm{PhD}$ supervisor, author of the reviewed book, the late C. A. Bayly, for his constant confidence, intellectual generosity, and friendship over more than one decade.Back to (1)

2. Ricardo Roque, Headhunting and Colonialism: Anthropology and the Circulation of Human Skulls in the Portuguese Empire, 1870?1930 (Basingstoke, 2010).Back to (2)

3. Eugene F. Irshchik, Dialogue in History: Constructing South India, 1795?1895 (Berkeley, CA, 1994). Back to (3)

4. In colonial studies, back in the early 1990s, this crucial deconstructive gesture only compares, perhaps, to anthropologist Michael Taussig?s parallel developments on colonial violence as a gauge of the colonizers? imaginary horror of the ?Indian as Wild Man? in his Colonialism, Shamanism and the Wild Man (Chicago, IL, 1987). This connection is purely my own, for Taussig is not mentioned in C.

A. Bayly?s work.Back to (4)

Source URL: http://www.history.ac.uk/reviews/review/2032

\section{Links}

[1] http://www.history.ac.uk/reviews/item/165271 